\title{
UMA HISTÓRIA SOCIAL DO FEMINISMO: DIÁLOGOS DE UM CAMPO POLÍTICO BRASILEIRO (1917-1937)
}

\author{
A Social History of Feminism: discussions within a Brazilian \\ political field (1917-1937)
}

Una historia social del feminismo: diálogos de un campo político brasileño (1917-1937)

GLAUCIA CRISTINA CANDIAN FRACCARO

Pontifícia Universidade Católica de Campinas - Campinas - SP, Brasil

http://dx.doi.org/10.1590/S2178-14942018000100002

Possui graduação em História pela Universidade Estadual de Campinas (2001), mestrado (2008) e doutorado (2016) em História Social do Trabalho pela Universidade Estadual de Campinas. Foi Coordenadora de Autonomia Econômica das Mulheres da Secretaria de Políticas para as Mulheres da Presidência da República. (galufraccaro@gmail.com)

Artigo recebido em 29 de agosto de 2017 e aprovado para publicação em 15 de dezembro de 2017. 


\section{RESUMO}

Este artigo oferece uma reflexão sobre a história do feminismo brasileiro a partir da perspectiva do mundo do trabaIho. As greves dos anos 1930, a atuação do Partido Comunista e as redes feministas internacionais anunciaram que o feminismo era um campo político em disputa desde seus primeiros momentos. Sustento 0 argumento de que não se tratava de casos excepcionais: a experiência das mulheres pode contribuir para uma interpretação que torne mais complexa a história da luta feminina por direitos do trabalho no Brasil.

PALAVRAS-CHAVE: Feminismo; Trabalhadoras; Política.

\section{ABSTRACT}

This article offers a reflection on the history of Brazilian feminism through the a perspective of the world of labor. The 1930s strikes, the role of the Communist Party and the international feminist networks announced that feminism was a disputed political field since its earliest moments. I argue that these are not exceptional cases: the experience of women can contribute to an interpretation that makes the history of the struggle for labor rights in Brazil more complex.

KEYWORDS: Feminism; Women Workers; Politics.

\section{RESUMEN}

Este artículo hace una reflexión sobre la historia del feminismo en Brasil desde la perspectiva del mundo del trabajo. Las huelgas en los años 1930, la actuación del Partido Comunista y las redes feministas internacionales anuncian que el feminismo há sido un campo político em disputa desde sus primeros momentos. Sostengo el argumento de que esos casos no eran excepcionales: la experiencia de las mujeres puede contribuir para una interpretación que haga de la lucha por los derechos laborales en Brasil más compleja.

PALABRAS CLAVE: Feminismo; Trabajadoras; Política. 
S o enredo favorito da história fosse a descoberta da transformação, as mulheres estariam, supostamente, excluídas das páginas por perturbar menos a ordem estabelecida. Pensar a história das mulheres, conduz, portanto, a considerar as relações entre os sexos, de modo a elucidar demasiadamente a perspectiva de "permanências e mudanças, das relações do sujeito e do objeto, da cultura e da natureza, do público e do privado". É Michelle Perrot (2005: 26) quem se debruça, a partir dos anos 1970, sobre os silêncios das mulheres na história para afirmar que, no mundo do trabalho, a categoria "gênero" parece mais pertinente e eficaz em todas as suas dimensões. A divisão de papéis e as funções sociais que emergem de uma conformação biológica, "uma vagina para receber, um ventre para carregar e seios para amamentar", marcariam o destino delas: "nenhum lugar além do lar" (Perrot, 2005: 173).

Há algum tempo que a historiografia enfrenta o desafio de perceber que o sujeito histórico não é universal, ao menos, desde Joan Scott (1988), ou ainda desde o artigo inovador de Gayle Rubin (1992), que evidenciou a existência de um sistema de sexo e gênero pelo qual um conjunto de arranjos da sociedade transforma a sexualidade biológica em produto de atividade humana'. Assim, é preciso considerar que a investigação da experiência de mulheres se justifica pelo fato de que a sexualidade, a maternidade e sua força de trabalho configuram relações de controle ou dominação distintas e, portanto, requerem um olhar específico (Lobo, 1991: 186). É bem verdade que, desde o tempo em que a historiadora francesa deu suas primeiras palestras sobre as mulheres e "os silêncios da história", já foi possível reunir muitos textos e pesquisas que romperam com esse quadro. No Brasil, os esforços para superar as ausências delas na história também envolveram a tentativa de compreender a vida das mulheres no mundo do trabalho (Rago, 2014; Esteves, 1989; Soihet, 1989).

Assim, proponho que considerar a experiência das trabalhadoras pode alterar a narrativa central sobre a História do Feminismo. As pesquisas em História e nas Ciências Sociais contribuíram para perpetuar a noção de que a classe trabalhadora havia faltado na emergência de um movimento feminista, exclusivo das elites letradas e das financeiras. Por consequência, os marcos conhecidos e celebrados do movimento brasileiro são quase que exclusivamente ações de mulheres de alta classe social. Um desses marcos é a fundação da Federação Brasileira pelo Progresso Feminino (FBPF), em 1922. Muita atenção foi dedicada à atuação da FBPF, organização liderada por Bertha Lutz, que seria a grande "orientadora do movimento feminista nacional"2. Branca Moreira Alves (1980: 127) e Heleieth Saffioti (1969: 258) inauguraram pesquisas que colocaram na história, em definitivo, o feminismo no Brasil, a atuação da federação e sua liderança.

Por outro lado, essa estratégia analítica redundou no que Mônica Schpun chamou de "centralidade de Bertha Lutz" (Schpun, 2002: 83) - para Branca Moreira Alves, a atuação da 
FBPF era concentrada no sufragismo, e Heleieth Saffioti demarcou que as ideias feministas eram estrangeiras e que ganharam força por meio da atuação de Lutz; de acordo com ela, "as manifestações feministas têm início no Brasil em consequência da visita da Dra. Bertha Lutz a Londres" (Saffioti, 1969: 257). Considerando a distância existente entre as mulheres que atuavam na FBPF e aquelas que trabalhavam em fábricas ou em postos menos favorecidos, as análises sobre esse período no Brasil tentaram responder justamente essa contradição.

A periodização sugerida por esses estudos demarca os diferentes momentos do feminismo por meio de "ondas", e a fundação da FBPF corresponderia à "primeira onda", quando a organização feminista se concentraria em conquistar o sufrágio das mulheres ${ }^{3}$. Até hoje, a história contada sobre elas procura compreender como um movimento desse caráter pretendia lutar pelos direitos das mulheres sem alterar os direitos dos homens, atuando por dentro das instituições governamentais. A explicação encontrada varia entre tratá-las como um "feminismo difuso", ou ainda como um "feminismo tático" 4 . Essas qualificações denotavam análises que esperavam, mas não encontraram, a plenitude da autonomia feminista nos seus "primórdios". De acordo com esse modelo, a "segunda onda" viria apenas nos anos 1960, fruto da "efervescência política do período", para problematizar os papéis públicos e privados das mulheres. Até mesmo para a "terceira onda" - para questionar as identidades diversas que compunham o feminismo, o elemento ausente seria a luta das mulheres no mundo do trabalho. É claro que os conflitos das relações de trabalho compuseram os diversos momentos do modelo, mas a separação por "ondas" costuma eleger marcos tidos como hegemônicos a cada período. 0 questionamento sobre o uso da metáfora das ondas tem sido cada vez mais frequente, por considerar que a periodização entrincheira a percepção do feminismo singular, na qual gênero é a categoria predominante de análise, deixando subsumidos os conflitos de raça e de classe (Laughlin e outras, 2010).

A classificação do movimento feminista também compôs os trabalhos que analisaram a existência dos circuitos do patriarcado na história do Brasil, e as pesquisas feitas até agora encontraram um sistema de gênero que excluía as mulheres e as mantinha confinadas nas funções domésticas e familiares. Entretanto, a suposta passividade delas, por estarem, talvez, ausentes das grandes greves, por serem excluídas de sindicatos e partidos, não é suficiente para compreendermos também por que o mundo mudou tanto para as mulheres durante todo o século XX. Não é possível afirmar categoricamente que a ausência numérica de mulheres nas instituições tenha desembocado numa total indiferença de gênero nas barganhas coletivas e políticas ou mantiveram intactas a ordem social e econômica. As greves dos anos 1930, a atuação do Partido Comunista e as redes feministas internacionais, abordados neste artigo, anunciaram 
que o feminismo era um campo político em disputa, desde os seus primeiros momentos. As mobilizações grevistas, por sua vez, além de representarem um forte indício da participação da classe trabalhadora no debate geral da legislação trabalhista, permitem entrever reivindicações e controvérsias que envolvam a experiência das mulheres no mundo do trabalho.

\section{BRÁS DO BRASIL, BRÁS DE TODO O MUNDO}

a cidade de São Paulo, depois da crise de 1929, mulheres e homens garantiam os
trabalhos nas fábricas, principalmente, nas tecelagens. O romance Parque Industrial, assinado por Mara Lobo, é um dos tesouros possíveis por meio do qual podemos caminhar pelas ruas do Brás. Mara Lobo é Patrícia Galvão, que escreveu o romance em 1933. Ela estava afastada do Partido Comunista e, por esse motivo, fez uso de pseudônimo. Depois de uma crise interna sobre a função dos intelectuais na organização política, a direção decidiu por "deixá-la à margem", que permanecesse apenas escrevendo. De acordo com Augusto de Campos, o Partido a considerava "agitadora individual, sensacionalista e inexperiente" (Campos, 1982: 102). A jovem de 21 anos é autora dessas linhas que, embora ficcionais, contam muito de como Patrícia Galvão enxergava o mundo do trabalho nos anos 1930. Ela descreve São Paulo como o maior centro industrial da América do Sul. Conta:

"A italianinha matinal dá uma banana pro bonde. Defende a pátria: - Mais custa! 0 maior é o Brás!" (Galvão, 2006).

Por meio de sua literatura, podemos acessar uma série de diálogos e interlocuções sociais. Podemos nos esgueirar pelo Brás de Pagu, que além de retratar a opressão das operárias e as péssimas relações de trabalho, de quebra, utilizou a literatura para alfinetar tanto 0 Partido Comunista, sobre a participação política das mulheres, quanto a pequena burguesia letrada, para ela, tão distante da realidade da classe trabalhadora. Esses, sim, alguns de seus marcantes interesses.

Embora apareçam na obra de Patrícia Galvão, fome, exploração e violência policial não eram mera ficção na vida da classe trabalhadora brasileira nos primeiros anos do século XX. A maior parte estava submetida a jornadas extenuantes que, em São Paulo, poderia atingir a marca de 16 horas diárias. Ausentes das fileiras sindicais, algumas dessas trabalhadoras 
não se fizeram ausentes das pressões por melhores relações de trabalho ou até mesmo das organizações grevistas.

Os anos 1930 haviam sido inaugurados com o célebre episódio da tomada da Bastilha do Cambuci, quando um motim tomou de saque a delegacia do Departamento de Ordem Política e Social. Em parte, a revolta provinha do sistema de identificação individual de trabaIhadores a serviço da polícia e dos donos de fábrica. 0 sistema de identificação não foi uniforme e era operado pelo DOPS, pelos donos de fábrica, por meio das circulares do Centro dos Industriais de Fiação e Tecelagem e pelo Departamento Estadual do Trabalho, que pretendia regular a vida profissional de cada pessoa. A origem desses prontuários guarda relação íntima com as circulares elaboradas pelos industriais, atentos aos conflitos nas relações de trabalho (Negro e Fontes, 2001).

As greves se espalharam por diversas fábricas. Essas mobilizações eclodiram face aos efeitos da Crise de 1929, que se agravara internacionalmente. Desemprego e redução dos salários tornavam as condições de vida mais difíceis; os empresários repassavam os custos da crise em forma de aumento da jornada de trabalho, que havia sido reduzida para conter estoques e produção de mercadoria, sem aumento dos salários. Esses eram os motivos que agitaram as greves iniciadas logo após a posse do governo que havia operado a Revolução de 1930.

Com a chegada de Getúlio Vargas e da Aliança Liberal ao poder, foi estabelecido o projeto de governo corporativista e de conciliação de classes, que convocava as instituições a desempenharem funções de colaboração, cujas primeiras ações foram a aprovação de decretos para regular as relações de trabalho. 0 projeto de conciliação aliancista dava seus primeiros passos ao nomear um tenentista como interventor do estado de São Paulo e ao trazer o Partido Comunista do Brasil (PCB), que se organizava desde os anos 1920 e sofrera perseguição de diversas naturezas para a legalidade (Araújo, 1998: 162).

As primeiras ações do governo de Vargas consistiram em fundar o Ministério do Trabalho, Indústria e Comércio e promulgar os decretos que instituíam juntas de conciliação de julgamento, ampliar a seguridade social e estruturar um aparato de fiscalização para a aplicação e o cumprimento das leis, além de regularem o trabalho de mulheres e crianças (Silva e Corrêa, 2016: 12).

No começo dos anos 1930, as greves atingiram várias categorias e cidades do interior do estado de São Paulo, e a condução do movimento ganhou novas disputas que envolviam diversas correntes de esquerda (Araújo, 1998: 181). Trabalhadores do setor têxtil, organizados na União dos Operários em Fábricas de Tecido (UOFT), mobilizaram mais de 15 mil pessoas, e José Righetti, principal liderança da organização têxtil, ganhou notoriedade ao organizar um grande comando de greve (Araújo, 1998: 177). 
A UOFT começou suas atividades ainda em 1917 e se reorganizou no início dos anos 1930. Em agosto de 1931, depois de encampar uma grande greve têxtil que, de acordo com 0 sindicato, mobilizou a paralisação de 68 mil pessoas em 14 dias, a UOFT enviou ao interventor do estado de São Paulo um memorial de reivindicações que deveria chegar até o Ministério do Trabalho - o que de fato aconteceu. 0 documento assinado por José Righetti circulou tanto no Ministério quanto na Secretaria do Gabinete Civil de Vargas, onde foi encontrado. As anotações nesses papéis indicavam que as autoridades haviam consultado os empresários sobre o líder sindical - de acordo com eles, Riguetti fazia do sindicato sua renda e era "responsável pela perturbação do trabalho paulista". No documento, o sindicalista descrevia que a proporção entre mulheres e homens na categoria têxtil chegava a $85 \%$ e que os patrões davam preferência à contratação de mulheres, a ponto de afirmar:

"Tendo em conta ainda que nas seções de tecelagem só aceitam mulheres, contribuindo desta forma para avolumar cada vez mais o número de homens desempregados, oferecendo, assim, um espetáculo ao mesmo tempo ridículo, vergonhoso e revoltante: o de ver a mulher na fábrica e o marido em casa, cuidando dos serviços domésticos e levar as crianças ao portão das fábricas para serem amamentadas"7.

A avaliação sofrida de José Righetti lamentava o papel de cuidados que os maridos das tecelãs tiveram de assumir. Para o sindicalista, os serviços domésticos e o trato com as crianças eram tarefas exclusivas das mulheres, tanto quanto a troca dessas funções entre homens e mulheres era concebida por ele como de menor valor, posto que não passava de algo "ridículo", "vergonhoso" e "revoltante". A noção de que existe uma massa de trabalho relegada tão somente às mulheres não era invisível a quem tivesse de lidar com o cotidiano da classe trabalhadora, mas isso não é o mesmo que dizer que havia um reconhecimento do peso que o desempenho do trabalho doméstico em cuidados e limpezas tinha na vida das mulheres. Por meio das palavras do sindicalista é possível demonstrar como relações sociais desiguais transformam diferenças biológicas em construções sociais (Kessler-Harris, 2007: 32). 0 sindicalista tinha uma visão de classe baseada na dignidade masculina, que em nada se apresentava como "universal".

Essas eram as reivindicações da UOFT: que se aplicasse a licença-maternidade sem prejuízo dos vencimentos; que fosse promovida a proteção à infância e a à velhice, e "que os lugares ocupados hoje por mulheres nas indústrias fossem, numa porcentagem crescente, de mês a mês, ocupados por homens, até a extinção do total do elemento feminino nas indústrias" 8 . Beirava o imponderável ignorar a presença das mulheres na força de trabalho, ao ponto de que quase todo o longo documento em questão versava sobre a exploração vivida 
por elas; por outro lado, a solução encontrada pelo sindicalista José Righetti seria a de eliminar a presença delas no mercado de trabalho formal. Os panfletos que tratavam dos motivos das greves de 1931 e 1932 explicavam que o grau de exploração prejudicava os homens, o que resultava em "um considerável número de chefes de família sem pão para seus filhos" 9 . Se por um lado, essa direção sindical considerava limpeza e cuidados como tarefas exclusivas das mulheres tecelãs, por outro, a mesma direção reforçava que o papel dos homens, como provedores familiares, era o de garantir o sustento, de modo que, na visão de sua liderança, preservar os postos e salários deles eram formas de penhorar o bem-estar do núcleo familiar.

Valiosa por ser numerosa e mobilizada, a disputa sindical pela base têxtil traria novos elementos para a atuação da UOFT. Em 1931, Righetti teve de montar uma operação rígida na porta do lugar onde estava acontecendo aa reunião da organização para impedir a participação de dirigentes do $P C B^{10}$. A presença de membros de outros sindicatos e da federação operária nas reuniões da entidade denotava que a relativa independência política, que a UOFT teria cultivado entre 1931 e 1932, configurava um atrativo para que outras correntes de esquerda participassem da mobilização da entidade. Os comunistas consideraram que essas entidades independentes, como a UOFT, configuravam um "gênero particular de base tradeunista" (Araújo, 1998: 167). Seria uma tarefa difícil a de manter o PCB longe das reuniões da organização, em meio a reorganização sindical da cidade.

É possível que a disputa sindical envolvesse a prática de infiltrar militantes na categoria têxtil. Em 1933, a tecelã Rachel Pilar, de 21 anos, desceu de um trem que vinha de Sorocaba para São Paulo em busca de um emprego na Fábrica de Tecidos Jafet. Ela vivia com parentes no Ipiranga, e foi demitida do trabalho por faltar muito ao serviço. No seu encalço por mais de um ano, por suspeita de pertencer ao PCB, o DOPS a deteve para identificação, sem muito sucesso, pois até aquele momento não se sabia ao certo se ela se chamava Rachel Freitas, Rachel Alves ou Maria Paiva. O cunhado da tecelã, interpelado pela polícia, afirmou que ela "costumava se recolher tarde da noite", e, que por ser ela comunista, a família decidiu colocá-la para fora da casa" ${ }^{11}$. Não é possível saber se o cunhado acobertava a tecelã de Sorocaba ou se, de fato, ela agora contava com a própria sorte para viver na Cidade, mas é provável que a tarefa da militante tenha sido a de se alistar na base da UOFT.

Ao mesmo tempo da chegada de "Rachel" na cidade de São Paulo, a UOFT passou a convocar "camaradas" para a reunião da entidade que, ainda muito preocupada com a situação dos homens "substituídos por mulheres e menores", também passou a difundir a exploração sofrida por elas e pelas crianças. Isso ao menos nos panfletos. 0 programa geral incorporou a necessidade da luta revolucionária "independente da conquista de reivindica- 
ções", e inseriu no pleito: licença de um mês após o parto, com vencimentos, cumprimento integral da lei de férias e da jornada de oito horas e "salário igual, para trabalho igual" 12 . Até 1932, a entidade havia se posicionado pouco sobre as diferenças entre homens e mulheres nas relações de trabalho das fábricas, mas durante seus esforços para organizar uma tabela unificada de preços para a manufatura de tecidos, recomendou que ela fosse confeccionada de forma a pagar "igual preço para igual tecido", porque a diferença de valores variava entre $20 \%$ e $50 \%$ na remuneração de homens e mulheres ${ }^{13}$.

"Rachel" tinha visitado o Uruguai, na companhia de Tarsila do Amaral, para uma reunião do comitê contra a guerra. Com ela, trouxe panfletos e jornais do Paraguai e da URSS que denunciavam a opressão vivida pelas mulheres, e sobre as jornadas de trabalho de mais de 12 horas exercidas pelas trabalhadoras domésticas de Montevidéu ${ }^{14}$. Porém, o partido que Rachel e Tarsila conheceram e no qual militavam tinha alterado a direção sobre as mulheres havia pouco tempo.

Em geral, as mulheres eram vistas como parte da luta de emancipação de toda a classe trabalhadora, e no fim dos anos 1920 muitas instâncias do Partido já fomentavam comissões femininas ou de mulheres cuja tarefa era de convidá-las a engrossar as fileiras da revolução ${ }^{15}$. A orientação política estabelecida pela Internacional Comunista, em 1922, visava a "preparar uma base orgânica política legal" e a propiciar a conquista do que chamavam de pequena burguesia para o proletariado. A troca de cartas e o envio de orientações partidárias entre a direção e os núcleos do PCB revelaram que, naqueles anos, o número de mulheres que integraram as fileiras comunistas era muito baixo: entre 20 e 50. De acordo com os dirigentes, "isso mal dá $3 \%$ de todo o Partido"16. As trabalhadoras domésticas figuraram como uma preocupação para a organização da classe, ao menos desde a formação do Comitê das MuIheres Trabalhadoras. "As mulheres que alugam seu braço nos palácios da burguesia, assalariadas, portanto", ao que tudo indica. 0 debate sobre elas estaria em torno de construir uma entidade de classe pela categoria ou reuni-las em um outro sindicato, cujo setor fosse similar, como o da indústria de alimentos ${ }^{17}$.

Dessa forma, a partir de 1922, o Partido se esforçou para tributar o dia 8 de março como uma jornada de lutas das mulheres. Algumas células se queixavam da falta de possibilidades de cumprir a tarefa por haver poucas mulheres mobilizadas, mas viam nas fábricas um potencial de atuação ${ }^{18}$. Menos que uma demanda proveniente dos quadros brasileiros, o debate sobre a mulher trabalhadora provinha da alta direção, que orientava para uma organização bem executada do 8 de março, capaz de alertar as trabalhadoras privadas dos direitos políticos e da vida política do Brasil. Como sugestão, a direção afirmava que as palavras de ordem 
deveriam versar sobre a vida real das trabalhadoras, e assim elas deveriam ser anunciadas: jornada de sete horas, proteção delas como mão de obra, proteção à maternidade, instalação de creches e "trabalho igual, salário igual"19.

A incorporação das mulheres na luta geral da classe trabalhadora, do ponto de vista dos comunistas, sofreu uma mudança em 1930. As mulheres, no Partido Comunista, vistas como companheiras da revolução e de revolucionários, ao menos nos textos que chegavam e eram publicados no Brasil, a partir de 1930 obtiveram um programa que tratava da igualdade e dos direitos relativos às trabalhadoras ${ }^{20}$. Uma parte dos elementos que explicam a mudança programática residia no debate internacional posto pelo feminismo. 0 texto que redirecionava a questão das mulheres afirmou que, para eles, a burguesia havia realizado "um trabalho particularmente enérgico entre as trabalhadoras, com o objetivo de alijá-las da luta de classes", usando reivindicações "neutras" e criando associações femininas especiais; contra essas iniciativas, os dirigentes se viram atuando de forma insuficiente, e acreditavam que a tarefa do Partido deveria ser "desmascarar a tentativa, mostrando que unicamente a luta pela revolução oferece a base para a emancipação da mulher trabalhadora"21.

\section{FEMINISMO E O MUNDO DO TRABALHO}

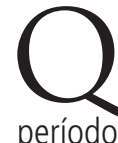

uanto ao "trabalho enérgico", elaborado pela burguesia, certamente os comunistas se referiam ao fortalecimento das organizações feministas no mundo todo, durante o período entreguerras. Muito mais conhecidas por levantarem a bandeira do voto feminino, na verdade, desde o fim do século XIX, as feministas estabeleceram longas discussões sobre a necessidade de elaboração de uma legislação trabalhista específica para as mulheres, porém a divisão de opiniões nem sempre estava claramente separada em grupos definidos (Wikander, 2010). A partir da proposta de um tratado de direitos iguais, elaborada para a Liga das Nações, em 1926, por integrantes da British Six Point Group e da National Woman's Party, e dos Estados Unidos, o Equal Rights Treaty, iniciaram-se discussões e esforços políticos que dividiam as mulheres e seus grupos a respeito da adoção de convenções e legislações internacionais específicas para as mulheres (Miller, 1994: 220)22. Com grande visibilidade em Genebra, sede da Organização Internacional do Trabalho $\left(\right.$ OIT ${ }^{23}$, tais grupos geraram um impasse em torno da imbricada fórmula política que deveria servir como base para a igualdade econômica e civil, assim como para a proteção da maternidade.

A formação de organizações internacionais no entreguerras contou com uma forte mobilização das mulheres de diferentes países que lutavam por mais participação e ainda disputavam a elaboração de diretrizes para o trabalho. 0 debate internacional travado entre as organizações estava dividido entre as que acreditavam que a regulamentação traria al- 
gum ganho para toda a classe trabalhadora, como era o caso da OIT; entidades defensoras do feminismo por direitos iguais que defendiam que a redução da regulamentação, ou nenhum ordenamento, teria como efeito a redução da discriminação de gênero, e grupos que defendiam a regulamentação para ambos os sexos e toleravam apenas os regulamentos de gênero já existentes, como a proibição do trabalho noturno e a proteção à maternidade (Zimmerman, 2014: 9).

O Brasil participou dessa articulação entre fronteiras por meio da atuação de Bertha Lutz. O surgimento de uma organização feminista com proeminência nacional e reconhecida internacionalmente não foi ignorado pela esquerda organizada. 0 programa levantado pela International Alliance of Women, em 1927, entidade à qual a brasileira Bertha Lutz estava vinculada, foi abordado por integrantes do Partido Comunista, que consideraram que debater sufrágio universal, direitos civis, divórcio e a igualdade de condições era uma agenda "um pouco assustadora e perigosa, pois não tocava nem nos privilégios dos grandes, nem na miséria dos humildes" 24 . 0 direito de voto e o reconhecimento dos direitos civis da mulher, para 0 comunismo brasileiro, não seria suficiente para garantir a liberdade, "enquanto pesarem sobre ela, como sobre o conjunto da classe trabalhadora, a exploração do capital e o domínio da burguesia" 25 . A tensão internacional entre os grupos que se organizavam a partir de Genebra aparecia no repertório da imprensa de esquerda, na forma de traduções de artigo produzidos fora do País e, no calor do debate internacional, também se veiculava a ideia de que o comunismo "reclamava o direito de voto às mulheres" 26.

Dentro da organização anarquista, durante os anos 1920, destacaram-se iniciativas para a formação de grupos femininos que tratassem com especificidade a questão da trabalhadora. Muitas dessas iniciativas contaram com Maria Lacerda de Moura (Schpun, 2004). A Federação Internacional Feminina, que teve alguma atividade em 1922, e o Centro Feminino, a partir de 1924, proferiram palestras que abordavam o conformismo diante da dura realidade social e a importância da rebeldia para o grupo que se organizava em torno das ligas de bairros e do jornal A Plebe ${ }^{27}$. Consideravam a professora Leolinda Daltro e seus intentos eleitorais como "sentimentos politiqueiros da velha feminista constitucional" 28 . Junto com Bertha Lutz, Moura havia fundado a Liga para a Emancipação Intelectual da Mulher, que figurou como uma das organizações que davam sustentação para a FBPF. Pouco anos depois, sem convicção na organização política que tinha vivido, Moura se afastou das trincheiras da disputa dizendo-se "livre de igrejas" e "livre de muletas", reforçando até mesmo o individualismo, quando se acreditava livre, também, de contradições:

"Não sou do progresso feminino pró-voto da senhorita Bertha Lutz e nem do bando militarizado e catequista da Professora Daltro. Voto? - Nem secreto, nem masculino, nem feminino. [...] 
me sinto livre para respirar no campo aberto do meu individualismo, reivindicando o dever de ser humana" 29 .

Após a adoção das bandeiras de igualdade, o Partido Comunista subiu o tom das críticas à organização das mulheres, não só àquela desempenhada por Bertha Lutz, e, no campo de batalha formado em torno das campanhas eleitorais e da instalação da legislação trabalhista no Brasil, assumiu oposição às vozes que se propunham a emancipar as mulheres por meio da conquista dos direitos civis. Iveta Ribeiro, uma das editoras da Revista Feminina, que se dedicava a tratar desses temas dentro da tradição católica, enfatizava a natureza conservadora "do verdadeiro feminismo" e se sentia representada, em parte, pela bandeira da participação política hasteada pela FBPF, era assim vista nas páginas do Jornal do Povo:

"Nós desejaríamos que essas cretinas que ainda dividem a humanidade em machos e fêmeas, e não em explorados e exploradores, nós desejaríamos que elas nos dissessem o que é que as mulheres - não as "damas" - têm lucrado com a atividade das Berthas Lutz" ${ }^{30}$.

Tratava-se de um questionamento virulento. Ideais de igualdade entre mulheres e homens estavam em formação desde o século XIX, embora tivessem ganhado fôlego e impacto, no Brasil, depois das greves de 1917, na construção do movimento operário, no Partido Comunista e nas camadas médias da sociedade. Grupos diferentes de mulheres nutriam visões distintas sobre a cidadania feminina: as trabalhadoras tinham de enfrentar o sindicalismo que elaborava suas pautas a partir da experiência e da dignidade masculinas e inseriam demandas de licença-maternidade e igualdade salarial nas negociações de classe; as comunistas, reunidas em pequenos comitês, mais ativos no Rio de Janeiro do que em São Paulo, organizavam atos diminutos para o Dia da Mulher e se esforçavam para inserir a condição de trabalhadora no programa geral do Partido; e ainda, os grupos feministas organizados, como a FBPF, que tinham capilaridade nacional, atuando inclusive em assembleias estaduais de deputados, mantinham o diálogo com o governo e recebiam a pressão política das outras camadas sociais, principalmente, do mundo do trabalho.

A noção de cidadania para as mulheres era debatida em termos de direitos civis, que englobava o acesso ao voto e ao divórcio, da maternidade, da igualdade salarial e da proibição do trabalho noturno às mulheres, e se misturavam com perspectivas de proteção e de conquista de direitos. 0 diálogo, na maior parte das vezes, travado em fortes tons de discordância, entre diferentes grupos, estivera posto desde que se levantaram as primeiras resoluções e projetos para as mulheres, especialmente aquelas que estavam no mercado de trabalho. E a pergunta "o que é que as mulheres têm lucrado com as atividades das Berthas Lutz" orientou boa parte das pesquisas realizadas sobre o tema. 
A princípio, a FBPF havia se inserido no debate público, em 1922, a partir da campanha pelo sufrágio das mulheres, por considerar que as reformas da legislação civil não seriam "nem urgentes, nem oportunas" 31 . A organização liderada por Bertha Lutz afirmava que se mantinha atenta as mulheres de todas as classes sociais, porém, foi apenas em 1931, que a bandeira "salário igual, trabalho igual" passou a fazer parte, efetivamente, das reivindicações da entidade, tendo recebido força de resolução no Segundo Congresso Internacional Feminista $^{32}$. Cinco anos mais tarde, movida pelo estudo proposto pela OIT sobre a situação das mulheres em diversos países do mundo, a bióloga coordenou duas inovadoras proposições legislativas: a criação de um departamento nacional da mulher e um estatuto das mulheres ${ }^{33}$. Entre 1922 e 1936, há um grande fluxo de ideias e disputas, do Brasil e de fora do país, que marcaria a formulação da legislação nacional.

Entre um episódio e outro, houve também disputas e debates travados na imprensa que constantemente avaliavam o trabalho da FBPF e geravam pressões que explicam, ao menos em parte, as mudanças de posição da entidade e de sua dirigente, em que pese a própria existência e a atuação do movimento operário. A atuação de Lutz e da federação, considerada elitista desde sua época, não o foi sem receber as críticas de quem impetrava esforços para se organizar nas bases da sociedade.

Patrícia Galvão, ainda que pouco articulada com os comitês de mulheres do Partido Comunista e mais ligada ao que ela mais tarde chamaria de Comitê Fantasma, ao se referir à alta direção e à clandestinidade dessa militância, dedicou análises severas à forma como se criava o movimento feminista nacional e, por conseguinte, à FBPF. A amarga realidade da ficção de Parque Industrial não deixava de cutucar esse movimento político e a burguesia letrada da São Paulo dos anos 1930, o que pode nos levar a pensar que o romance não pretendia mesmo ser apenas um "texto social" a denunciar opressões e abusos seguindo o bê-á-bá da cartilha comunista. Estabelecia também um diálogo com outros grupos sociais de seu tempo - revelando-Ihes suas contradições. Em Parque Industrial, o personagem Alfredo, rico e conhecedor de Karl Marx, aparece solitário num "bar prostituto" do centro da Cidade, bebendo uísque. De acordo com o livro, ele acorda do porre com a chegada de "emancipadas, intelectuais e feministas que a burguesia de São Paulo produz":

- Acabo de sair do Gaston. Dedos maravilhoso!

- 0 maior coiffeur do mundo! Nem em Paris! [...]

- O Diário da Noite publicou uma entrevista na primeira página. Saí horrenda no clichê. Idiota esses operários de jornal! A minha melhor frase apagada! 
- Hoje é a conferência. Mas acho melhor mudar a hora das reuniões. Para podermos vir aqui! $[\ldots]$

Uma matrona de gravata e grandes miçangas aparece espalhando papéis.

- Leiam. 0 recenseamento está pronto. Temos um grande número de mulheres que trabalham. Os pais já deixam as filhas serem professoras. E trabalhar nas secretarias. Oh! Mas o Brasil é detestável no calor. Ah! Mon Palais de Glace.

- Se a senhora tivesse vindo antes, podíamos visitar a cientista sueca.

- Ah! Minha criada me atrasou. Com desculpas de gravidez. Tonturas. Esfriou demais o meu banho. Também já está na rua! ${ }^{34}$

Eu poderia arriscar uma referência: o diálogo entre as feministas do bar imaginado por Pagu, ao cogitar a visita da "cientista sueca", aludia à chegada da cientista Marie Curie ao Brasil. A doutora francesa, na verdade, aportou no cais do Rio de Janeiro no dia 15 de julho de 1926, e passou os 45 dias no País em reuniões e palestras, em boa parte das ocasiões, esteve com Bertha Lutz e Carlota Pereira de Queiroz ${ }^{35}$. Há de se considerar que a militante comunista, a partir do bar e do testemunho de Alfredo, havia entoado um diálogo direto com as feministas da época, apontando a elas as contradições - desenhadas como ricas, frequentadoras de salões de beleza a esnobar o trabalho de operários de jornal.

0 feito, em alguma medida, foi apresentado no livro em oposição à própria atuação de Galvão, que, por sua vez, realizava sua militância no alistamento em fábricas e células do partido; onde também, nem sempre, conseguia dar vazão às suas opiniões sobre maternidade, abusos, estupros ou discriminações. 0 diálogo do livro ainda deu relevo à vida das "criadas", sem as quais o feminismo de "gravata e miçangas" não conseguiria, definitivamente, participar de uma reunião com Marie Curie. A crítica à atuação limitada das feministas da FBPF veio no próprio tempo da entidade, e o movimento feminista brasileiro não se fez por um grupo só.

Patrícia Galvão aproveitava as oportunidades para fazer comentários sobre a formação do feminismo brasileiro, e, certamente, esse embate todo promoveu mudanças e ajustes nas atuações por todos os lados. Em um jornal de curta duração, no qual trabalhou ao lado de Oswald de Andrade, ela escreveu algumas colunas de opinião - o texto abaixo é um excerto de "Maltus Além", uma ironia com o nome do economista Thomas Malthus que defendia, grosso modo, o controle da natalidade como forma de regular a economia. 0 artigo foi publicado em 1932 na coluna "A Mulher do Povo", que integrava o jornal 0 Homem do Povo:

"Excluída a grande maioria de pequenas burguesas cuja instrução é feita nos livrinhos de beleza, nas palavras estudadas dos meninos de baratinha, nos gestos de artistas de cinema mais em 
voga ou no ambiente semi-familiar dos coquetéis modernos - temos a atrapalhar o movimento revolucionário do Brasil uma elitezinha de João Pessoa que sustentada pelo nome de vanguardistas e feministas berra a favor da liberdade sexual" ${ }^{\prime 3}$.

No texto, a colunista desferiu golpes duros ao grupo que se organizava na FBPF - ironizando as alianças feitas com deputados da Paraíba para a votação parlamentar do sufrágio, e, de quebra, denunciava que a proposta de voto das mulheres não era sustentada por uma visão popular de ampliação da participação eleitoral. Às voltas com a própria maternidade, cerceada por companheiros do Partido que a aconselhavam a sublimar a culpa e a ternura que o nascimento de Rudá havia provocado nela, Patrícia Galvão também atirava seus argumentos (Galvão, 2005). A frágil saúde do seu filho nos primeiros anos de vida, e a de outras crianças com quem ela conviveu em Santos, a colocava em alerta sobre a mortalidade infantil e as altas ocorrências de morte de mulheres em decorrência do parto nas famílias mais pobres. As frequentes críticas de Patrícia Galvão acionavam a circularidade de ideias sobre a igualdade entre mulheres e homens e a condição da trabalhadora.

Dessa forma, a FBPF não era uma organização única a tratar de projetos sobre cidadania feminina, em que pese o fato de ter recebido essas duras críticas durante sua atuação. Em 1935, as mulheres do Partido Comunista se organizaram na União Feminina do Brasil que, por sua vez, recebeu reprovação de Bertha Lutz por aceitarem a colaboração dos homens na condução do movimento. Em resposta, as militantes da entidade revelaram que a bióloga já havia aceitado o apoio dos homens ao participar de um partido para sua candidatura à Assembleia Nacional Constituinte de 1934, e que não admitiam a atuação eleitoral e restrita que, consideravam, vinha produzindo a FBPF:

"Se há algum ponto de contato com o nosso e seu programa, é prova de que as necessidades femininas são ainda as mesmas que antes da fundação de sua Federação, e, a prova de que nada foi feito [...] é que as mulheres resolveram se unir, e elas mesmas lutar pela conquista de seus direitos, sem esperar por associações inócuas" 37 .

As diversas opiniões e formulações que se empregaram sobre igualdade não só fizeram parte do repertório feminista como agiram diretamente sobre a formulação da legislação trabalhista. É preciso notar que a FBPF não se empenhou apenas em obter o direito de voto para as mulheres, nem esteve isolada das disputas que o campo da chamada emancipação feminina impunha. A distância entre as classes sociais, ainda que grande, somada às "discordâncias aborrecidas", revela uma "perversa operação de classe" (Kessler-Harris, 2001: 9).

Os efeitos obtidos pela organização de mulheres burguesas e provindas de países euroamericanos, medidos apenas pela natureza dos movimentos, não explicam a circulação 
dos ideais de igualdade e as disputas travadas entre as classes sociais na conquista dos direitos das mulheres (Rupp, 1997: 5-8). Havia mais no feminismo do que polêmicas (Savarsy, 1992). Por esse motivo, a polarização narrativa, a separar e a escalonar os campos do feminismo, não é uma estratégia capaz de produzir sínteses. As trajetórias de "Rachel", de Leolinda Daltro, de Bertha Lutz, de Patrícia Galvão, de Maria Lacerda de Moura, geralmente entendidas como casos isolados, como excepcionalidades, são histórias que podem ser compreendidas, a partir de suas disputas e no conjunto, de modo a revelar a história dos direitos das mulheres no Brasil. 0 feminismo se constituiu, no País, como um campo político, permeado por disputas e diferentes projetos de emancipação que compuseram o repertório sobre direitos e justiça social.

A história das mulheres não precisa ser caracterizada por seus silêncios. 0 acúmulo de pesquisas sobre elas, que considera a perspectiva de gênero e que remonta à história das trabalhadoras, entendido em seu conjunto, pode proporcionar a interpretação de que as noções de justiça social e direitos, no Brasil, estiveram diretamente ligadas às lutas por licença-maternidade e igualdade salarial. Por sua vez, as demandas das trabalhadoras criaram tensões no movimento feminista que alterou seu decurso de modo a rever programas, tidos como restritos desde seu surgimento. As narrativas que elegeram grupos hegemônicos como temas principais da história, a estabelecer "ondas", podem se tornar mais complexas ao serem consideradas a trajetória das trabalhadoras e suas demandas. A circularidade das noções de cidadania tampouco se restringia a São Paulo, a Genebra ou a Moscou, e é justamente a possibilidade de traçar essas redes que fornece uma interpretação mais ampla sobre os conflitos que conformavam os projetos de emancipação e justiça.

\section{NOTAS}

1 No campo da história, a categoria gênero escancarou os limites de se estabelecer um perfil único das muIheres ou ainda de uma "experiência feminina" (Samara, Soihet e Matos, 1997).

2 Gabinete Civil da Presidência da República. Série Correspondências. Carta a Lindolfo Collor - Ministro do Trabalho, 29/04/1931. Bertha Lutz (1894-1976). Foi educada na Europa e graduou-se em biologia na Sorbonne, em 1918. A FBPF foi fundada com o apoio de Carrie Chapman Catt, dirigente da National Woman Suffrage Association dos Estados Unidos.

3 Esse modelo é adotado por diversos estudos e pesquisas a partir de Celi Pinto (2007). Ver também: Marlise Mattos (2010).

40 feminismo difuso seria composto por mulheres de classe alta que atuavam na imprensa feminista alternativa dos primeiros anos do século XX (Pinto, 2007: 10). 0 "feminismo tático" que era exercido pela FBPF, que aproveitava ocasiões e possibilidades oferecidas pelas classes dominantes para garantir o exercício da 
cidadania, está em Raquel Soihet (2006: 28).

5 Não há uma única proposta historiográfica para dar conta dessa questão. Nancy Hewitt considera que é possível reformular o conceito de "ondas" de modo a reconhecer os elementos múltiplos e os conflitos que compreendem os diferentes períodos do ativismo feminista. Para a autora, os momentos distintos do feminismo questionaram, por eles mesmos, as fronteiras de classe e raça, assim denunciando os limites colocados por mulheres brancas (Hewitt, 2012: 659, 661, 665); (Hewitt e outras, 2010).

6 Nascido em 1893, José Righetti foi tecelão na fábrica Votorantin, no Ipiranga. Foi delegado da UOFT no $3^{\circ}$ Congresso Operário, no Rio de Janeiro, em 1920. Ainda nos anos 1920, foi membro do Centro Feminino Jovens Idealistas. Em 1931, foi classificado como um "agitador de greves", e os registros afirmam que ele costumava atacar as iniciativas do Ministério do Trabalho. Ver: Prontuário de José Righetti no Departamento de Trabalho Industrial, Comercial e Doméstico (1931). Secretaria do Gabinete Civil da Presidência da República, Série 17.10 Ministério do Trabalho, Lata 46. É possível encontrar atividade de Righetti desde as greves de 1917, quando, preso por poucas horas, algumas operárias foram até a delegacia pedir sua soltura. 0 Combate, de 11/09/1917.

7 Memorial de José Righetti (agosto de 1931). Secretaria do Gabinete Civil da Presidência da República, Série 17.10 Ministério do Trabalho, Lata 46.

8 Secretaria do Gabinete Civil da Presidência da República, Série 17.10 Ministério do Trabalho, Lata 46.

9 DEOPS. Prontuário UOFT 0124, v. 1.

10 Idem.

11 DEOPS. Prontuário 2496 Caixa 199, Rachel Alvez ou Rachel de Freitas ou Maria Paiva.

12 DEOPS. Manifesto da Comissão Executiva da UOFT (1933). Prontuário UOFT 0124, v. 1.

13 DEOPS. Panfleto da Comissão Executiva da UOFT (1932). Prontuário UOFT 0124, v. 1.

14 DEOPS. Prontuário 2496 Caixa 199.

15 "Las mujeres obreras frente al peligro guerrero". AEL, documentos da Internacional Comunista (IC).

16 "Aos camaradas da Sessão Feminina da Internacional Comunista", de 29/11/1929. AEL. Documentos da IC.

17 Idem.

18 A Nação, 19/09/1927.

19 "Au comitê central du Parti Communiste Brésilien", de 27/01/1930. IC. A orientação foi repassada em documento resumido e vertido para a língua portuguesa, em 10/02/1930. "Aos camaradas encarregados do trabalho entre as mulheres", de 10/02/1930. AEL, Documentos da IC.

20 A partir de 1930, Wendy Goldman verifica uma inversão na perspectiva sobre a família do ponto de vista soviético oficial: "Depois de começar com o compromisso feroz e libertário com a liberdade individual e a "extinção" da família, o período terminou com uma política baseada no fortalecimento repressivo da unidade familiar", referindo-se ao reforço da família e do papel da mulher como cuidadora e esteio da sociedade, muito defendida por Stalin (Goldman, 2010: 389). 
21 La Correspondência Sudamericana, de 15/02/1930.

22 A British Six Point Group foi uma campanha formada por mulheres britânicas, em 1921, que propunha seis pontos de mudança legislativa para os direitos, que incluía a demanda por direitos iguais entre mulheres e homens. Durante os anos 1920 foi ativa em pressionar a Liga das Nações para estabelecer um tratado internacional de equidade de direitos. A National Woman's Party foi uma organização norte-americana, formada em 1916, que, dentre outras coisas, lutou por uma emenda de direitos iguais na Constituição dos Estados Unidos, e que tinha grande peso na articulação internacional das mulheres.

23 Foi um organismo criado pela Liga das Nações, em 1919, para estabelecer padrões internacionais de trabalho, em nome da justiça social como forma de firmar a paz ao fim da violenta Primeira Guerra Mundial (1914-1919). A OIT estabeleceu em suas primeiras convenções que os estados que faziam parte da Liga das Nações deveriam proibir o trabalho noturno das mulheres e garantir licença-maternidade. Empregava um modelo tripartite de negociação, que envolvia empregadores, trabalhadores e Governo.

24 A Nação, de 03/01/1927. A International Alliance of Women foi fundada, originalmente, como uma organização sufragista. (Rupp, 1997: 21).

25 A Nação, de 05/01/1927.

26 "As feministas e nós", tradução de artigo do jornal Le Ouvriére (Paris), por A. Gillea. Publicado em A Nação, de 22/04/1927.

27 A Plebe, de 10/11/1923.

28 A Plebe, de 02/10/1919. Leolinda Daltro havia se destacado com a campanha pelo alistamento eleitoral de mulheres e, em 1910, fundou no Rio de Janeiro o Partido Republicano Feminino. Em 1919, se candidatou à intendência do município.

29 A Manhã, de 09/12/1928.

30 Jornal do Povo, de 12/10/1934.

31 FBPF, Caixa 42, Pacote 1, vol. 30.

32 Resoluções do Segundo Congresso Internacional Feminista, 1931 (cópia enviada ao ministro do Trabalho). Ministério do Trabalho 17.10, Lata 46.

33 Câmara dos Deputados. 0 Trabalho Feminino: A mulher na ordem econômica e social, Imprensa Nacional, 1937. p. 23. FBPF, Caixa 37, Pacote 1, Dossiê 2.

34 Idem, p. 76.

35 Carlota Pereira de Queiroz (1892-1982),formada em medicina, organizou centenas de mulheres durante 0 levante paulista de 1932 e foi a única mulher eleita deputada constituinte em 1933.

360 Homem do Povo, de 27/03/1932.

37 A Manhã, de 30/05/1935. 


\section{REFERÊNCIAS BIBLIOGRÁFICAS}

ALVES, Branca Moreira. Ideologia e feminismo: a luta da mulher pelo voto no Brasil. Petrópolis: Vozes, 1980.

ARAÚJO, Ângela M. A construção do consentimento: corporativismo e trabalhadores no Brasil nos anos 30. São Paulo: Scritta/Fapesp, 1998.

ESTEVES, Martha. Os populares e o cotidiano do amor no Rio de Janeiro da Belle Époque. Rio de Janeiro: Paz e Terra, 1989.

GOLDMAN, Wendy. Mulher, Estado e revolução: política familiar e vida social soviéticas, 1917-1936. São Paulo: Boitempo/lskra Edições, 2014.

HEWITT, Nancy A. Regenerating the wave metaphor. Feminist Studies, v. 38, n. 3, p. 658-680, 2012.

et al. No permanent waves: recasting histories of U.S. feminism. New Brunswick/New Jersey/Londres: Rutgers University Press, 2010.

KESSLER-HARRIS, Alice. In pursuit of equity: women, men and the quest for economic citizenship in 20th-Century America. Oxford University Press, 2001.

LAUGHLIN, Kathleen A.; GALLAGHER, Julie; COBBLE, Dorothy S.; BORIS, Eileen; NADASEN, Premilla; GILMORE, Stephanie; ZARNOW, Leandra. Is it time to jump ship? Historians rethink the waves metaphor. Feminist Formations, v. 22, n. 1, p. 76-135, 2010.

LOBO, Elisabeth S. A classe operária tem dois sexos: trabalho, dominação e resistência. São Paulo: Brasiliense, 1991. p. 186.

MATOS, Maria Izilda. Percursos e possibilidades na historiografia contemporânea. Cadernos Pagu, v. 1, n. 6 , 1998.

MATTOS, Marlise. Movimento e teoria feminista: é possível reconstruir a teoria feminista a partir do Sul global? Revista de Sociologia Política, v. 18, n. 36, p. 15-23, 2010.

MILLER, Carol. Geneva - the key for equality: inter-war feminists and the league of nations. Women's History Review, n. 2, p. 220-221, 1994.

NEGRO, Antônio L.; FONTES, Paulo. Trabalhadores em São Paulo: ainda um caso de polícia. 0 acervo do DEOPS paulista e o movimento sindical. In: No coração das trevas: o DEOPS/SP visto por dentro. São Paulo: Arquivo do Estado/Imprensa Oficial do Estado, 2001.

PINTO, Céli R. Uma história do feminismo no Brasil. São Paulo: Fundação Perseu Abramo, 2007.

RAGO, Margareth. Do cabaré ao lar: a utopia da cidade disciplinar. Rio de Janeiro: Paz e Terra, 2014.

RUBIN, Gayle. Thinking sex: notes for a radical theory of the politics of sexuality. In: VANCE, Carole S. Pleasure and dangersexuality exploring female sexuality. Londres: Pandora, 1992. p. 267-293. 
RUPP, Leila. Worlds of women: the making of an international women's movement. Princeton University Press, 1997.

SAFFIOTI, Heleieth. A mulher na sociedade de classes: mito e realidade. Petrópolis: Vozes, 1969.

SAMARA, Eni; SOIHET, Raquel; MATOS, Maria Izilda. Gênero em debate: trajetórias e perspectivas na historiografia contemporânea. São Paulo: Educ, 1997.

SCHPUN, Mônica R. Carlota Pereira de Queiroz era antifeminista? (ou de como pensar os contornos do feminismo). In: COSTA, Lima; SCHMIDT, Pereira (Org.). Poéticas e políticas feministas. Florianópolis: Mulheres, 2002.

SCOTT, Joan. Gender and politics of history. Columbia: University Press, 1988.

SILVA, Fernando T.; CORRÊA, Larissa R. The politics of justice: rethinking Brazil's corporatist labor movement. Labor: Studies in Working-Class History of the Americas, v. 13, n. 2, 2016.

SOIHET, Raquel. O feminismo tático de Bertha Lutz. Florianópolis: Edusc, 2006.

WIKANDER, Ulla. Demands on the ILO by International Organized Women in 1919. In: VAN DAEL et al. ILO histories: essays on the international organization and its in the world during the twentieth century. Genebra: Peter Lang, 2010. p. 67-89.

ZIMMERMAN, S. Night work for night women and bonded labour for womem of colour? In: KIMBLE, S. et al. New perspectives on European women's legal history. Nova York: Routledge, 2014. 